\title{
The effectiveness of a pressure clinic in preventing pressure sores
}

\author{
H Dover RGN ONC DNCert, ${ }^{1}$ W Pickard RGN ${ }^{2}$ I Swain PhD C Eng MIEE ${ }^{3}$ D \\ Grundy FRCS ${ }^{4}$
}

\begin{abstract}
${ }^{1}$ Community Liaison Sister, ${ }^{2}$ Clinical Nurse Specialist in Spinal Rehabilitation, ${ }^{3}$ Principal Medical Physicist, ${ }^{4}$ Consultant Surgeon, The Duke of Cornwall Spinal Treatment Centre and Department of Medical Physics, Odstock Hospital, Salisbury, Wiltshire SP2 8BJ, England.
\end{abstract}

The role of a pressure clinic in reducing the incidence of pressure sores is described. Interface pressures are routinely measured to ensure that appropriate cushioning is provided. In patients most at risk, thermography is also valuable to ensure that the blood flow to the skin is not compromised. The implementation of such a clinic has proved successful and has resulted in a reduction of over $50 \%$ both in the incidence of sores and in the admission rate due to sores, when compared with studies from other spinal units.

Key words: pressure sores; prevention; pressure clinic.

\section{Introduction}

Pressure sores are still distressingly common following spinal cord injury. We believe the term 'pressure sore' is preferable to 'decubitus ulcer' or 'bed sore', as it is more correct, stresses the main cause of the condition and is more easily understood both by patient and carers. Prevention of sores by regular relief of pressure and use of suitable support surfaces are straightforward concepts which are evidently still not adequately appreciated in some district general hospitals. ${ }^{1}$ Certainly the incidence of pressure sores in the acute stage of spinal cord injury along with other complications is dramatically lowered by early admission to a spinal injuries unit. ${ }^{2,3}$

However, pressure sores after discharge from hospital are also a big problem, and follow up by a spinal injuries unit is no guarantee that these will be avoided. For instance Archibald ${ }^{4}$ found that over $50 \%$ of ex-patients from a spinal unit reported at follow up of having had a pressure sore, and Lawes $^{5}$ found that $15 \%$ of patients discharged from 2 British spinal injuries units were later readmitted because of sores. The concept of pressure clinics to prevent pressure sores was developed by Rogers at Rancho Los Amigos Hospital, ${ }^{6}$ the techniques being further refined by other spinal injury centres. ${ }^{7-10}$ These were the reasons why a pressure clinic was incorporated into the Duke of Cornwall Spinal Treatment Centre at Odstock Hospital, Salisbury, from the outset.

\section{The pressure clinic}

The day to day running of the clinic, which is staffed by a nursing sister assisted by an occupational therapy technician, has recently been described by Rothery. ${ }^{11}$ The important points to stress are as follows:-

1 Patients are taught to take responsibility for their own well being, including care of their pressure areas, and this is reinforced repeatedly by all staff in the patient's primary care team, ie nurse, doctor, physiotherapist, occupational therapist and social worker.

2 A comprehensive education programme is provided to enable the patient to understand the causes and prevention of pressure sores.

3 The patient attends the pressure clinic both during inpatient rehabilitation and at each outpatient follow up.

4 The educational and preventive programme is continued by a community liaison nurse who visits patients in their home after discharge. 


\section{Methods of assessing pressure areas}

\section{Interface pressures}

Interface pressures are routinely measured, using a Talley Skin Pressure Evaluator, with a $100 \mathrm{~mm}$ diameter pressure sensor (Fig 1). The latter consists of a matrix of copper contacts on its internal surfaces. The sensor is inflated and the contacts broken when the pressure in the sensor equals the externally applied pressure. This is recorded as the interface pressure.

Where, as is usually the case, a cushion is used that distributes weight equally, eg the foam, pin-core latex and single manifold Roho cushion, the use of 2 sensors over the ischial tuberosities alone should be sufficient. Ideally, dynamic interface pressures should be taken with the patient in different situations going about his or her daily life. Unfortunately, this is not practicable in the average clinical situation but we find the following method satisfactory. With the patient dressed, the sensor is placed under the ischial tuberosity, between the clothing and the surface of the cushion. Falsely high readings can be obtained when the sensor is used to measure pressures on fluid or air filled cushions, especially on Roho cushions. In such cases the sensor should be taped directly onto the skin. Care is taken not to place any tape across the face of the sensor or over the copper contacts. Falsely low readings can be obtained when the $100 \mathrm{~mm}$ sensor is used over a small area such as a heel or ischial tuberosity in an excess-

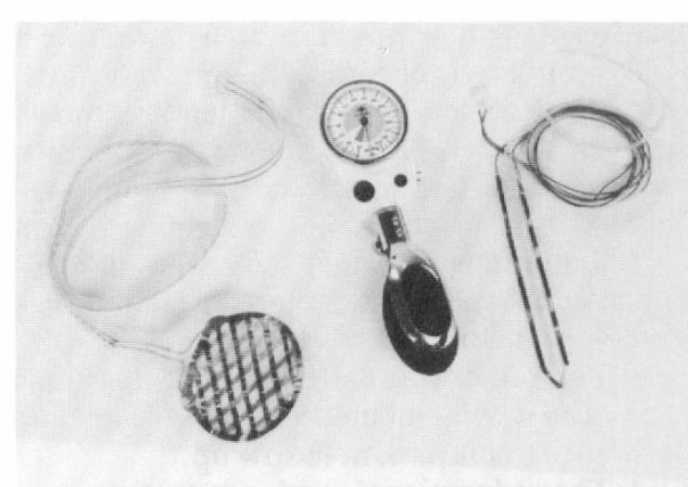

Figure 1 Talley skin pressure evaluator with 2 sensors, $100 \mathrm{~mm}$ diameter on left and $28 \mathrm{~mm}$ diameter on right. ively thin patient eg one with a flaccid paraplegia. In such cases the sensor will act as a small air cuff, redistributing pressures until the last of the contacts is broken. This is particularly unfortunate as these patients often have high interface pressures and mark excessively. In such circumstances smaller $28 \mathrm{~mm}$ sensors can be taped directly onto the skin.

In order to exclude errors due to the sensors being held in a curved position, they should initially be taped directly onto the skin over the ischial tuberosities, with the patient on his or her side with the hips and knees at $90^{\circ}$. Baseline pressures are then recorded. When using a cushion designed to redistribute pressure away from the ischial tuberosities onto the posterior trochanteric shelves eg the ischial cut-out cushion, interface pressures should be recorded over these 4 areas (Fig 2). The patient is then dressed and lifted onto the wheelchair cushion and the pressures remeasured. The baseline pressures are subtracted from the latter pressures to obtain the actual interface pressures. ${ }^{12}$

If the patient is unable to relieve pressure by lifting in the chair, leaning from side to side or by leaning forwards, a safe interface pressure is $35 \mathrm{~mm} \mathrm{Hg}$. If pressure can be relieved, an interface pressure of $60 \mathrm{~mm} \mathrm{Hg}$ should be safe. These figures are guidelines only, and may not always be attainable in practice. If sensation is present, higher pressures may be tolerated for longer periods.

\section{Thermography}

Although the measurement of interface pressures can give guidelines as to acceptable levels of pressure, it does not give any indication as to how the skin reacts to that pressure. Bader and Gant ${ }^{13}$ showed that transcutaneous oxygen tension $\left(\mathrm{TcPO}_{2}\right)$ was reduced by externally applied pressure. They found considerable variation in the reduction of $\mathrm{TcPO}_{2}$ levels between normal controls and patients with a variety of neurological conditions. Shakespeare and Swain ${ }^{14}$ showed that the effect of pressure on $\mathrm{TcPO}_{2}$ levels also varied according to the blood flow in the cutaneous circulation.

Thermography offers a simple means of 


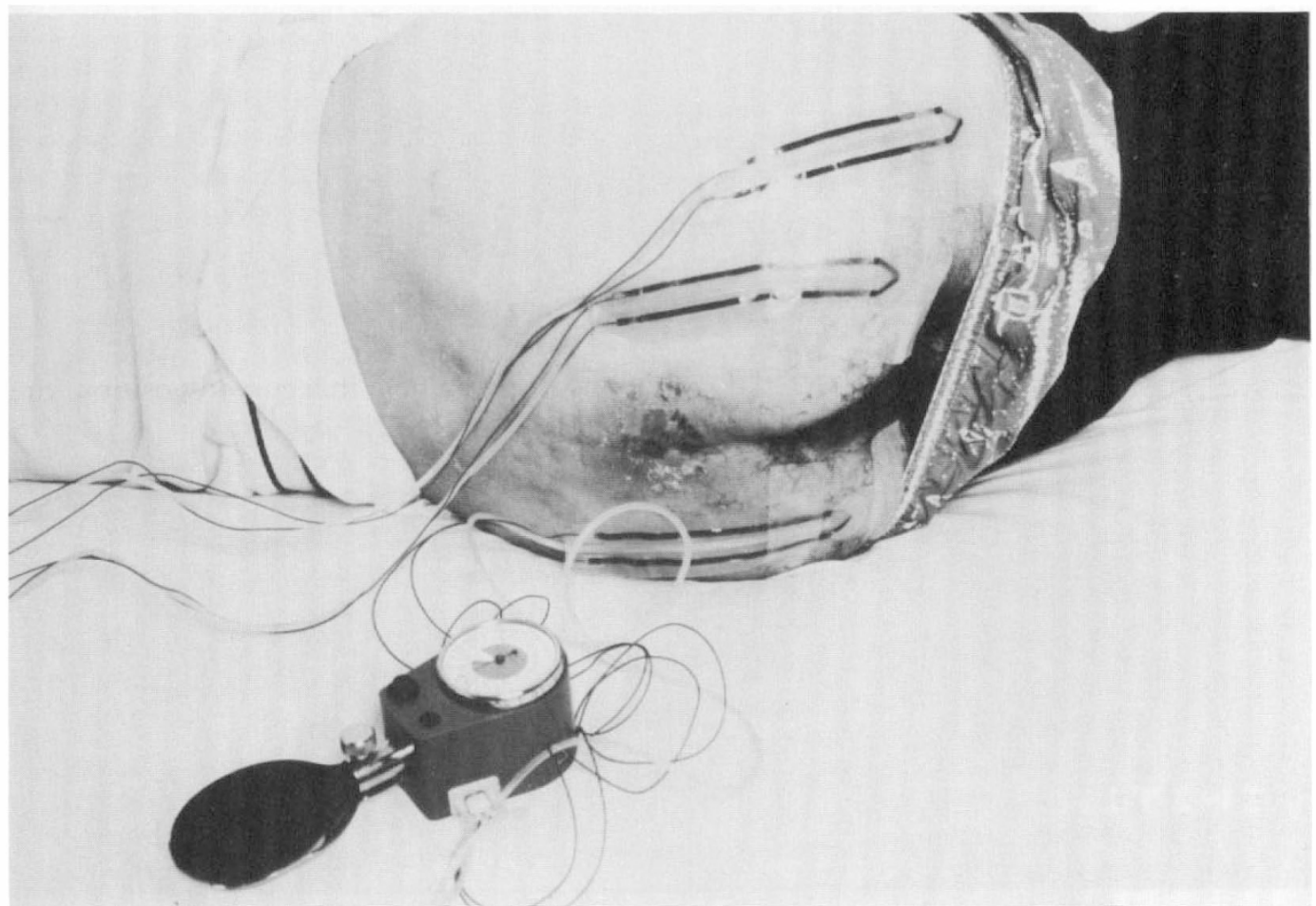

Figure 2 Four $28 \mathrm{~mm}$ sensors taped over the ischial tuberosities and posterior trochanteric shelves.

determining the effect of pressure in those patients most at risk, the principle being that if the applied pressure is sufficient to decrease the blood flow to the skin, a hyperaemic response will occur when that pressure is removed. ${ }^{15}$

However, Bar ${ }^{16}$ measured skin temperature and colour as well as interface pressures, to gauge the tissue response to applied pressure to an area. He identified a biphasic response characterised by (1) local increase in blood flow to the deep tissues, detected by an increase in skin temperature, and (2) a secondary flushing of the skin, visible as erythema. The extent of these responses depended on the mean applied pressure to the area. A prolonged increase in blood flow to the deep tissues, following the disappearance of the secondary erythematous phase, occurred when the mean interface pressures were greater than $90 \mathrm{~mm}$ $\mathrm{Hg}$. He therefore showed that erythema is not as reliable an indicator of deep tissue trauma as is the measurement of surface temperature.
In the method developed in Salisbury, the patient is seated on the cushion under test for at least 30 minutes and is then quickly lifted onto a bed on his or her side (in the same position as described above for application of the $28 \mathrm{~mm}$ pressure sensors). Clothing is removed and an initial image is taken using an Agema $782 \mathrm{SW}$ infra-red camera, which allows for continuous measurement, as well as providing the ability to store selected images. The maximum hyperaemic response usually occurs 4 to 6 minutes after the pressure has been removed and can last up to 40 minutes (Fig 3).

Guidelines as to the choice of cushion for a particular patient have already been described by Rothery. ${ }^{11}$ In the majority of patients, recordings of interface pressures are sufficient to enable the appropriate cushion to be chosen, but thermography is occasionally useful as an additional procedure, in order to determine the most suitable seating surface for patients with particular problems, for instance patients 
a

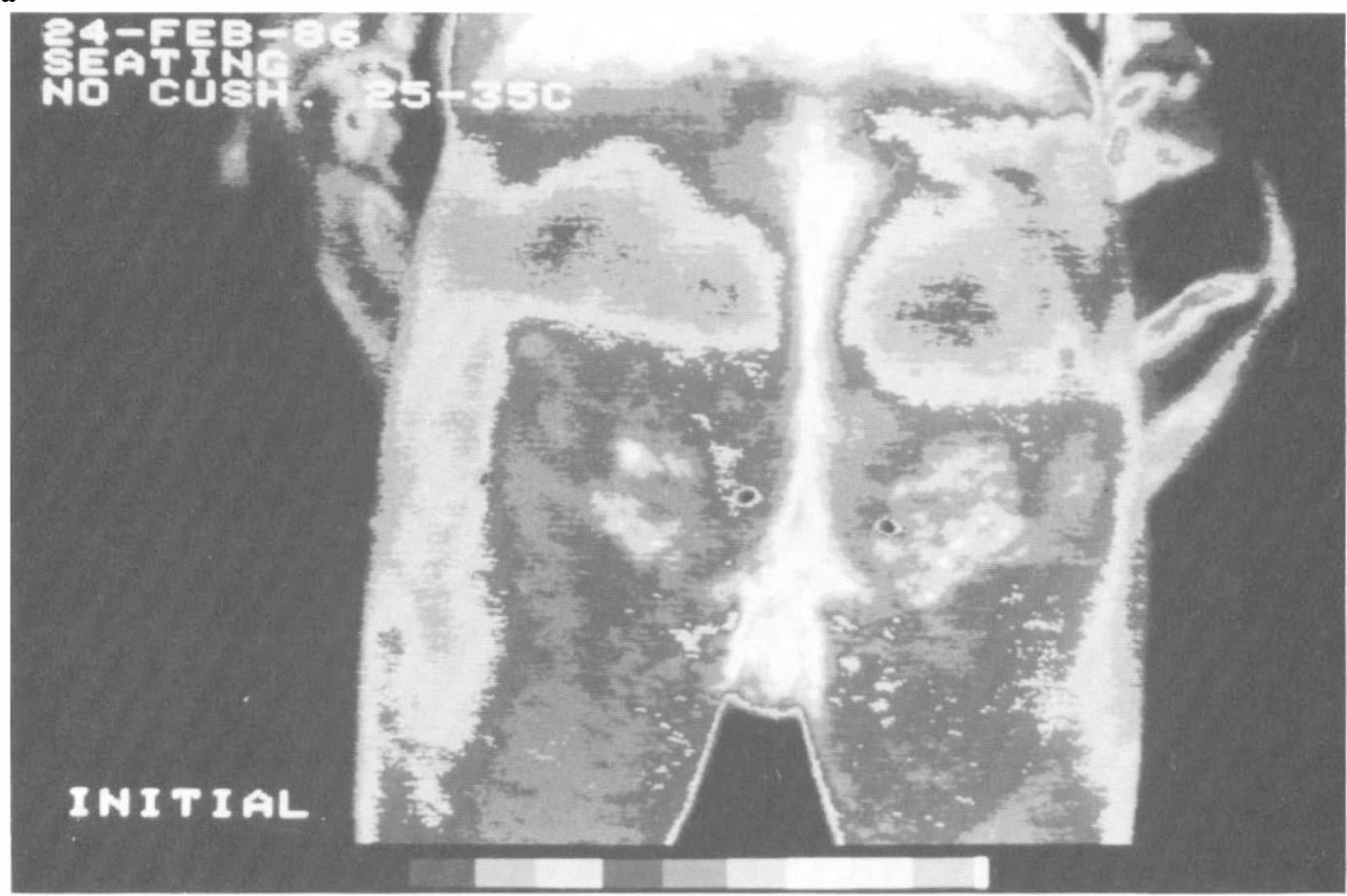

b

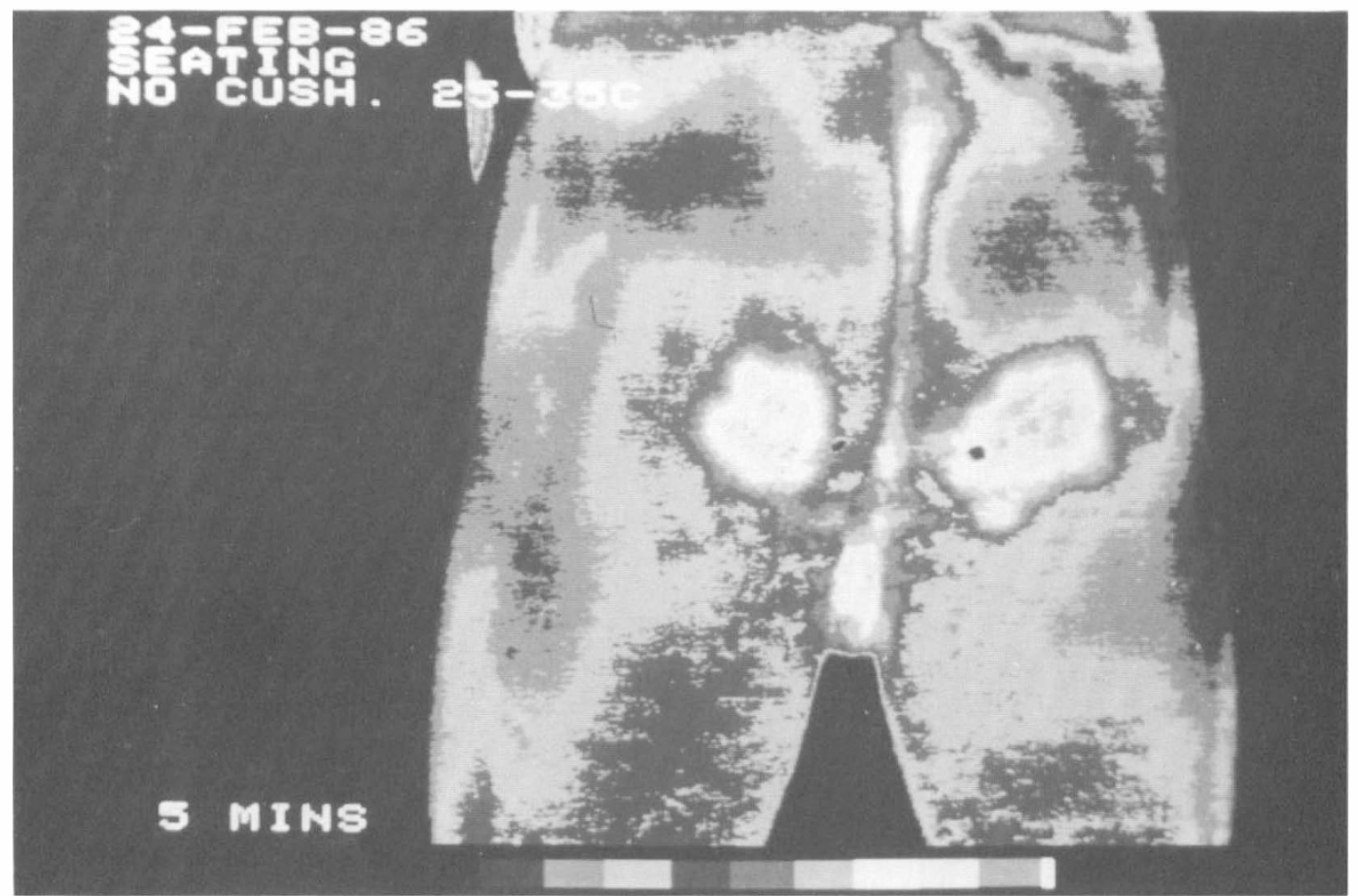

Figure 3 Thermographic images in normal volunteer, demonstrating active hyperaemia over ischial tuberosities (a) immediately and (b) 5 minutes after rising from a wheelchair sling seat, without a cushion. 
Table I Incidence of pressure sores (ischial, sacral or trochanteric) in patients injured between January 1984 and December 1987

\begin{tabular}{lccc}
\hline Initial rehabilitation & Number of patients & $\begin{array}{c}\text { Patients with pressure } \\
\text { sores }\end{array}$ & $\begin{array}{c}\text { Patients requiring readmis- } \\
\text { sion to spinal unit for sores }\end{array}$ \\
\hline $\begin{array}{l}\text { Salisbury } \\
\text { (Group A) }\end{array}$ & 135 & $11(8.1 \%)$ & $5(3.7 \%)$ \\
$\begin{array}{l}\text { Other spinal } \\
\text { units (Group B) }\end{array}$ & 10 & $3(30 \%)$ & $3(30 \%)$ \\
\hline
\end{tabular}

with severe muscle wasting associated with a flaccid paraplegia, or patients with marked pelvic obliquity.

\section{The present study}

Rothery ${ }^{11}$, although reporting on a 2 year follow up of patients seen in the pressure clinic, rightly stated that this was not a sufficiently long period to assess fully the effectiveness of the clinic in the prevention of pressure sores.

The study has therefore been extended to 2 groups of patients who developed their paraplegia or tetraplegia between January 1984 and December 1987. Patients not requiring wheelchairs indoors were excluded from the study.

\section{Group A}

One hundred and thirty-five patients had completed their rehabilitation in Salisbury and had been followed up as outpatients. Their spinal cord paralysis was of traumatic origin in 126 and nontraumatic in 9. Eleven $(8.1 \%)$ developed ischial, sacral or trochanteric sores of whom $5(3.7 \%)$ required readmission (Table I).

\section{Group B}

One hundred and sixty-five patients had been rehabilitated in other spinal units and were attending as outpatients in Salisbury for the first time. Of these only 10 had sustained their spinal cord paralysis between January 1984 and December 1987 and these patients were studied.
In 9 the paralysis was of traumatic origin, and in one of nontraumatic origin. Three patients developed sores $(30 \%)$, and all required readmission.

\section{Discussion}

The establishment of a pressure clinic as the central part of the educational programme for the prevention of pressure sores has proved to be very effective. Our results compare favourably with those reported from other spinal units $\mathrm{s}^{4,5}$ and show a reduction of over $50 \%$ both in the incidence of pressure sores and in the readmission rate due to sores. We believe this is due to the great emphasis placed on education of the patient and carers by the pressure clinic staff and members of the primary care team.

The pressure clinic acts as an information source for both inpatients and outpatients. Patients at home are free to telephone with queries - for instance, they may request advice about potential 'at risk' areas on the skin, or they may wish to discuss the purchase of a new cushion, wheelchair or mattress. Additional advice is given by the community liaison nurse on a home visit.

Hospital and community staff within the spinal unit catchment area are offered training in the long term management of spinal cord injured patients, with an emphasis on the prevention of pressure sores. Only by continued attention to detail and regular follow up, both in hospital and the community, will the incidence of pressure sores be reduced.

\section{References}

1 Egerton J, Grundy D, Russell J (1986) ABC of spinal cord injury. Nursing. Br Med J 292: 325-329.

2 Donovan WH, Carter RE, Bedbrook GM, Young JS, Griffiths ER (1984) Incidence of medical 
complications in spinal cord injury: patients in specialised, compared with non-specialised centres. Paraplegia 22: 282-290.

3 Carvell J, Grundy D (1989) Patients with spinal injuries. Early transfer to a specialist centre is vital. $\mathrm{Br}$ Med J 299: 1353-1354.

4 Archibald R (1982) A co-ordinated programme of follow-up care. Reported, but unpublished study, Edenhall Spinal Injuries Unit, Edinburgh.

5 Lawes CJ (1984) Pressure sore readmission for spinal injured people. Care, Science and Practice 4(2): 4-8.

6 Rogers, JE (1973) Tissue trauma group. In: Annual Report of Progress, Rehabilitation Center at Rancho Los Amigos Hospital.

7 Key, AG, Manley MT, Wakefield E (1978) Pressure redistribution in wheelchair cushion for paraplegics: its application and evaluation. Paraplegia 16: 403-412.

8 Ferguson-Pell MW, Wilkie IC, Reswick JB, Barbenel JC (1980) Pressure sore prevention for the wheelchair-bound spinal injury patient. Paraplegia 18: 42-51.

9 Noble PC (1981) The prevention of pressure sores in persons with spinal cord injuries. Monograph 11. International Exchange of Information in Rehabilitation, New York.

10 Ferguson-Pe!l MW (1983) Seating for patients vulnerable to pressure sores In: Barbenel JC, Forbes CD, Lowe GDO editor. Pressure Sores, Macmillan London: 15-25.

11 Rothery FA (1989) Preliminary evaluation of a pressure clinic in a new spinal injuries unit. Paraplegia 27: 36-40.

12 Robertson JC, Shah J, Amos H, Druett JE, Gisby J (1981) An interface pressure sensor for routine clinical use. Eng Med 9: 151-156.

13 Bader DL, Gant CA (1988) Changes in transcutaneous oxygen tension as a result of prolonged pressures at the sacrum. Clin Phys Physiol Measure 9: 33-40.

14 Shakespeare PG, Swain ID (1985) Skin blood flow and $\mathrm{TcPO}_{2}$ measurement. Biological Engineering Society Conference Proceedings, Dundee: 78-87.

15 Black R, Filippone AF (1980) Thermography in a seating program. Digest of the 8th Canadian Medical and Biological Engineering Conference: 167-168.

16 Bar CA (1989) The response of tissue to applied pressure. PhD Thesis, University of Wales, Cardiff. 